\title{
SISTEM PENDUKUNG KEPUTUSAN PEMILIHAN JURUSAN MENGGUNAKAN METODE MULTIFACTOR EVALUATION PROCESS DI SMK MUHAMMADIYAH 7 GONDANGLEGI KABUPATEN MALANG
}

\author{
Muhammad Ramadhani Alfatih ${ }^{1}$, Rini Agustina ${ }^{2}$. \\ Sistem Informasi, Universitas Kanjuruhan Malang ${ }^{1,2}$ \\ 666rams.alfatih@gmail.com ${ }^{1}$, riniagustina@unikama.ac.id ${ }^{2}$
}

\begin{abstract}
Abstrak. Manusia akan selalu bertemu dengan masalah dalam pengambilan atau pemilihan sebuah keputusan. Pemilihan jurusan di Sekolah Menegah Kejuruhan (SMK) salah satu permasalahan pengambilan atau pemilihan keputusan yang dihadapi oleh siswa Sekolah Menengah Pertama (SMP) yang hendak memasuki jenjang diatasnya. SMK Muhammadiyah 7 Gondanglegi Kabupaten Malang merupakan salah satu sekolah yang masih menerapkan sistem manual dalam pemilihan jurusan yang tersedia disekolah tersebut.Berdasarkan atas permasalahan diatas, Dibuatlah sebuah Sistem Pendukung Keputusan (SPK) yang dapat membantu memilih jurusan dengan menggunakan metode Multifactor Evaluation Process (MFEP). Dan dari hasil User Acceptance Test (UAT) terhadap sistem ini menghasilkan tingkat kepuasan siswa sebesar $80,8 \%$.
\end{abstract}

Kata Kunci: Sistem Pendukung Keputusan, MFEP.

\section{PENDAhUluan}

Dalam hidup manusia akan selalu bertemu dengan permasalahan pengambilan atau pemilihan keputusan. Contoh kasus dalam pengambilan atau pemilihan keputusan yaitu pemilihan jurusan pada Sekolah Menengah Kejuruhan (SMK) yang dialami oleh siswa-siswi kelas IX Sekolah Menengah Pertama (SMP). Masalah tersebut juga menjadi dilema untuk siswa-siswi SMP yang ingin bersekolah di SMK Muhammadiyah 7 Gondanglegi Kabupaten Malang. Banyaknya jurusan yang tersedia di SMK tersebut membuat para siswa perlu mempertimbangankan ulang keputusan mereka dalam memilih jurusan. Banyak faktor yang dapat mempengaruhi siswa-siswi untuk mengambil jurusan yang tepat untuk mereka. Dari segi faktor internal seperti kemampuan dari akademik, bakat, dan minat siswa itu sendiri. Dan dari segi faktor eksternal bisa jadi karena terbawa teman-teman mereka, lingkungan, atau juga karena keinginan orang tua untuk siswa tersebut memasuki sebuah jurusan. Faktor-faktor tersebut dapat men-support siswa tersebut namun juga dapat menjadi bumerang yang dapat menghambat mereka untuk berkembang.

Dengan perkembangan teknologi informasi masa kini dapat bermanfaat untuk melihat kemampuan siswa-siswa tersebut sehingga mereka dapat berkembang dalam jurusan yang sesuai dengan mereka. Hal ini juga dapat mengurangi resiko ketidak cocokan siswa-siswa terhadap suatu jurusan sehingga tidak menimbulkan kerugian antara pihak siswa-siswi itu sendiri dan juga pihak sekolah.

Maka dibuatlah Sistem Pendukung Keputusan dalam pemilihan jurusan yang bertujuan dapat membantu dan mendukung siswa-siswi dalam memilih jurusan dengan menggunakan metode Multifactor Evaluation Process (MFEP). Harapan penulis tentang Sistem Pendukung Keputusan ini dapat membantu siswa-siswi SMP kelas 3 dalam memilih jurusan sekolah 
terutama yang ada di SMK Muhammadiyah 7 Gondanglegi agar sesuai dengan kemampuan, bakat, dan minat mereka.

\section{METODE PENELITIAN}

\subsection{SISTEM PENDUKUNG KEPUTUSAN (SPK)}

Sistem Pendukung Keputusan adalah proses dalam mengambil sebuah keputusan yang terkomputerisasi sehingga dapat membantu dalam pengambilan keputusan untuk menyelesaikan masalah yang tidak terstrukur (Cahyatullah, 2017).

\subsection{METODE MULTIFACTOR EVALUATION PROCESS (MFEP)}

Metode Multifactor Evaluation Process (MFEP) adalah sebuah metode berbentuk kuantitatif dengan weighting system dalam mengambil keputusan berbentuk multifaktor, secara subjektif dan juga intuitif dalam menimbang berbagai faktor yang berpengaruh penting terhadap alternatif pilihan mereka (Muhammad Dahria, Ishak, 2014).

langkah-langkah melakukan perhitungan dalam metode MFEP menurut Martuasa (2015), yaitu:

1. Pertama menentukan faktor dan juga bobot faktor dengan total pembobotanya yaitu factor weight diharuskan sama dengan $1(\Sigma$ pembobotan $=1)$.

2. Memasukan nilai tiap-tiap faktor yang memiliki pengaruh dalam pengambilan keputusan dari data-data yang nantinya diproses, bentuk nilai yang dimasukkan itu sendiri berupa nilai objektif, yaitu factor evaluation yang memiliki nilai antara 0 sampai dengan 1.

3. Weight evaluation merupakan proses perhitungan antara factor weight dan factor evaluation kemudian dijumlahkan dengan seluruh hasil weight evaluations menghasilkan total hasil evaluasi.

Perhitungan Multifactor Evaluation Process (MFEP) dirumuskan sebagai berikut:

$$
\begin{aligned}
\mathrm{WE} & =\mathrm{FW} \times \mathrm{FE} \\
\Sigma \mathrm{WE} & =\Sigma(\mathrm{FW} \times \mathrm{FE})
\end{aligned}
$$

$$
\begin{aligned}
& \text { Keterangan }: \\
& \mathrm{WE}=\text { Weighted Evaluation } \\
& \mathrm{FE}=\text { Faktor Evaluation } \\
& \mathrm{FW}=\text { Faktor Weight } \\
& \Sigma \mathrm{WE}=\text { Total Weighted Evaluation }
\end{aligned}
$$

\section{HASIL DAN PEMBAHASAN}

\subsection{PERHITUNGAN MFEP}

Kelayakan siswa dilihat dari faktor-faktor yang menunjang kelayakan dengan kriteria jurusan yang tersedia, Nantinya akan terlihat kecocokan siswa tersebut terhadap jurusan yang mana. Langkah-langkahnya sebagai berikut:

1. Menentukan Factor weight

Dalam mementukan factor weight di peroleh dari hasil wawancara dan observasi di sekolah dengan guru bagian kesiswaan SMK Muhammadiyah 7 Gondanglegi akan ditunjukan dalam tabel berikut:

Tabel 1. Tabel Faktor Weight.

\begin{tabular}{|c|c|c|}
\hline Faktor & Bobot Faktor & Weight \\
\hline Akademik & $40 \%$ & 0.4 \\
\hline Bakat & $60 \%$ & 0.6 \\
\hline Jumlah & & 1 \\
\hline
\end{tabular}

2. Menentukan Factor Evaluation

Dalam menentukan factor evaluation berdasarkan faktor-faktor yang ditentukan seperti sebagai berikut: 
a. Rata-rata nilai akademik

Nilai akademik terdiri dari nilai matematika, bahasa indonesia, bahasa inggris, dan tes potensi akademik (TPA). Kemudian dalam menghitung bobot factor evaluation nya akan dijadikan bilangan decimal. Untuk rumus mencari nilai

Rata-rata dari nilai akademik sebagai berikut:

Rata-rata $=($ Nilai Matematika + Nilai Bahasa Indonesia + Nilai Bahasa Inggris + Nilai Tes Potensi Akademik) : 4

Bobot $=$ Rata-rata $: 100$

b. Rata-rata nilai bakat

Berdasarkan hasil wawancara dan observasi di SMK Muhammadiyah 7 Gondanglegi mendapatkan soal tes bakat yang terdiri dari numerik, spasial, figural, 3D, visual, urutan, verbal, sistematis, dan kosa-kata. Lalu untuk kriteria bakat dalam jurusan antara lain sebagai berikut:

1. Perbankan

Bakat : Numerik, sistematis, figural.

2. Teknik Kendaraan ringan

Bakat : Numerik, 3D, Visual.

3. Administrasi Perkantoran

Bakat : Numerik, sistematis, figural.

4. Perhotelan

Bakat : Urutan, figural, spasial.

5. Tata boga

Bakat : 3D, spasial, visual.

6. Teknik Sepeda Motor

Bakat : Numerik, 3D, visual.

7. Teknik Ototronik

Bakat : Numerik, 3D, visual.

8. Teknik Instalasi Tenaga Listrik

Bakat: Numerik, 3D, visual.

9. Teknik Alat Berat

Bakat : Numerik, 3D, visual

10. Teknik Komputer Jaringan

Bakat : Visual, Numerik, Urutan.

11. Multimedia

Bakat : Verbal, Visual, Spasial

12. Keperawatan

Bakat : Visual, urutan, 3D

13. Farmasi

Bakat : Visual, urutan, 3D 
Dan untuk rumus rata- rata nilai bakat sendiri dirumuskan sebagai berikut:

Rata-rata $=($ Bakat 1+ Bakat 2+Bakat 3) $: 3$

Bobot $=$ Rata-rata $: 100$

Pada tahap hasil penelitian telah diambil Nilai hasil tes yang telah dilakukan siswa-siswi dan dapat dilihat pada tabel berikut:

Tabel 2. Nilai tes siswa

\begin{tabular}{ccccc}
\hline No & Mata Pelajaran & Desi Fitria t. S. & $\begin{array}{c}\text { Nama siswa } \\
\text { Novi Dwi a. }\end{array}$ & Diaz Rossi v. \\
\hline 1 & b. Indonesia & 80 & 80 & 90 \\
\hline 2 & b. Inggris & 80 & 70 & 90 \\
\hline 3 & matematika & 80 & 70 & 70 \\
\hline 4 & tpa & 80 & 70 & 80 \\
\hline 5 & numerik & 80 & 60 & 90 \\
\hline 6 & spasial & 80 & 80 & 20 \\
\hline 7 & figural & 80 & 60 & 30 \\
\hline 8 & 3 d & 80 & 70 & 70 \\
\hline 9 & visual & 80 & 50 & 60 \\
\hline 10 & urutan & 80 & 60 & 80 \\
\hline 11 & verbal & 80 & 70 & 50 \\
\hline 12 & sistematis & 80 & 90 & 50 \\
\hline 13 & kosakata & 80 & 30 & 40 \\
\hline
\end{tabular}

Setelah mendapatkan nilai hasil tes yang telah dilakukan oleh siswa. Factor Weight telah ditentukan. Kemudian di dihitunglah factor evaluation sesuai perhitungan yang di jelaskan pada tabel dibawah ini

Tabel 3. Tabel factor evaluation

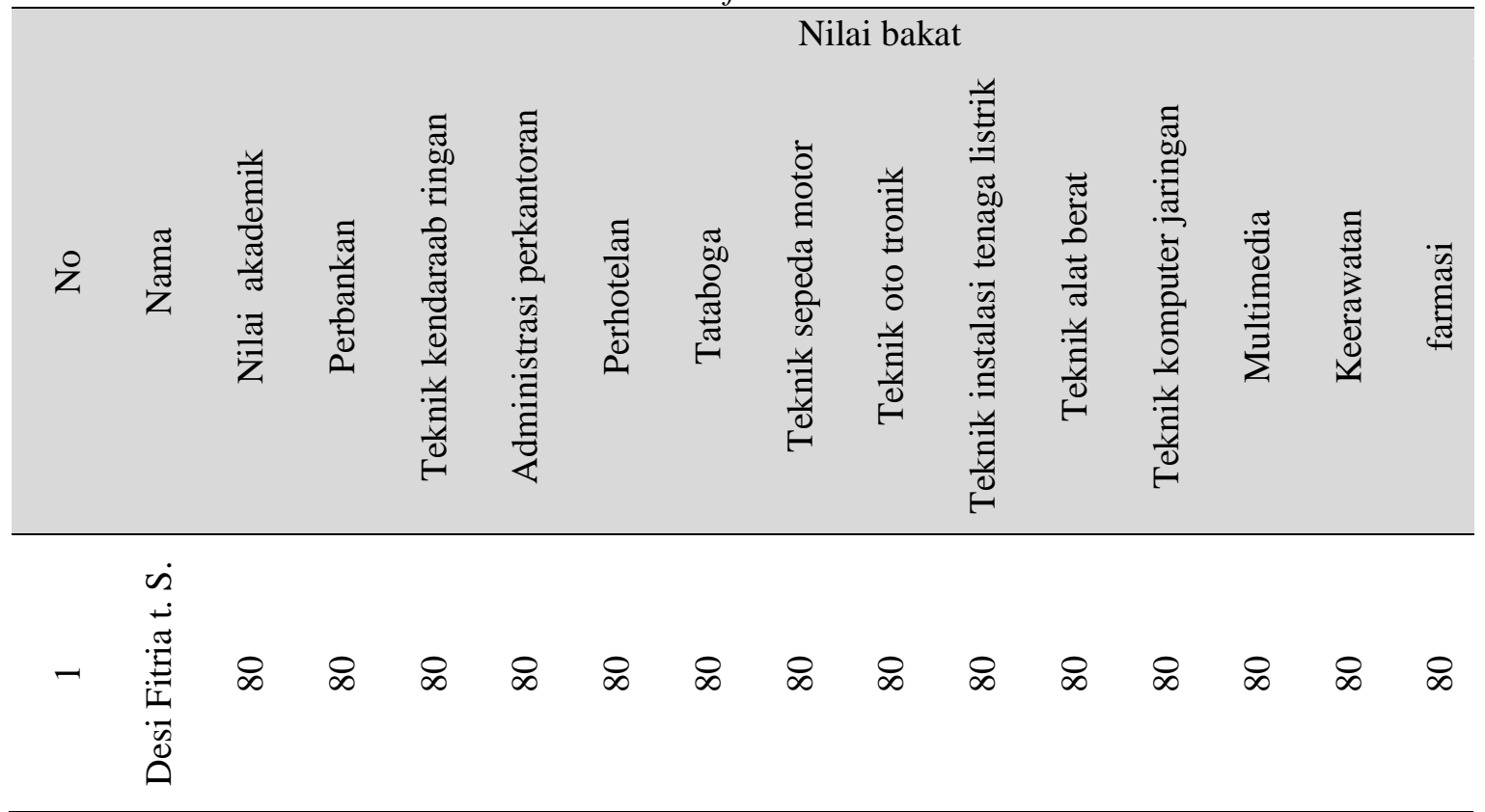




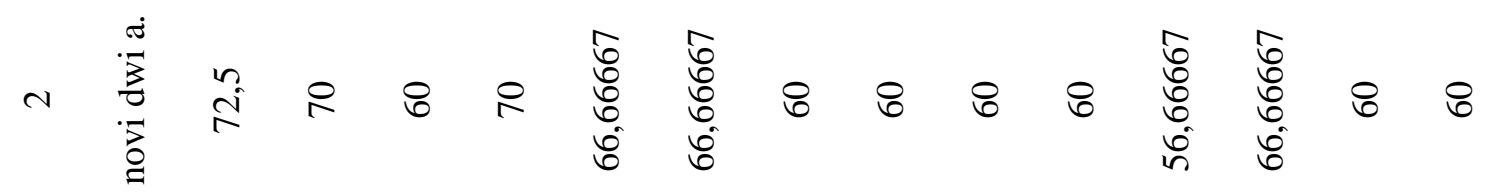

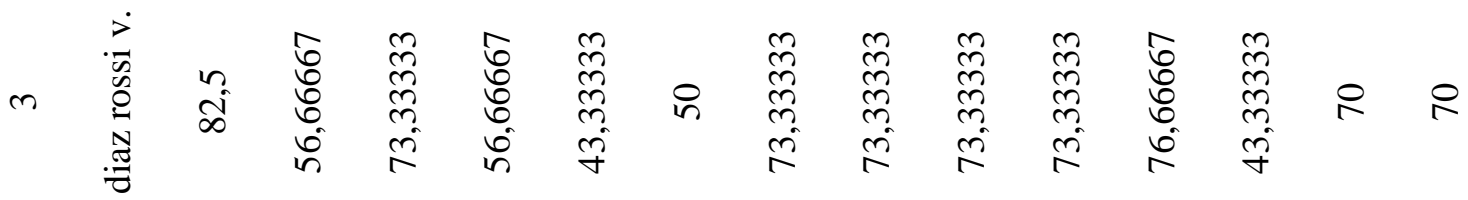

3. Menentukan Total Weighted Evaluation

Dalam menentukan total dari Weighted evaluation yaitu melakukan perkalian antara factor weight dengan factor evaluation. Berikut adalah tabel total weighted evaluation :

Tabel 3. Total Weighted Evaluation

\begin{tabular}{ccccccc}
\hline Faktor & Factor weight & & Factor evaluation & & Weighted evaluation \\
\hline Akademik & 0.4 & $\mathrm{X}$ & Nilai Akademik & $=$ & Weighted Akademik \\
\hline Bakat & 0.6 & $\mathrm{X}$ & Nilai Bakat & $=$ & Weighted Bakat \\
\hline Total & & & & $=$ & 1 \\
\hline
\end{tabular}

total weighted evaluation di jelaskan pada tabel berikut ini :

Tabel 4. Total Weighted Evaluation

\begin{tabular}{|c|c|c|c|c|c|c|c|c|c|c|c|c|c|c|}
\hline \multirow[b]{2}{*}{$\stackrel{\circ}{z}$} & \multirow[b]{2}{*}{$\begin{array}{l}\underset{\Xi}{\tilde{E}} \\
\text { Zू }\end{array}$} & \multicolumn{13}{|c|}{ Jurusan } \\
\hline & & 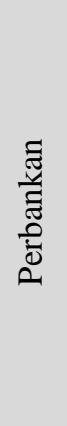 & 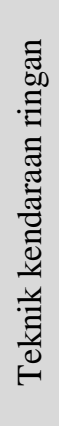 & 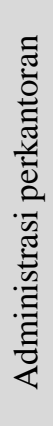 & $\begin{array}{l}\frac{\tilde{\sigma}}{0} \\
\frac{0}{0} \\
\frac{0}{0} \\
0\end{array}$ & 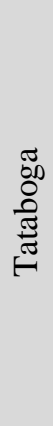 & 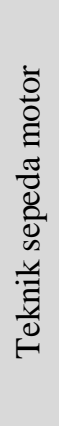 & 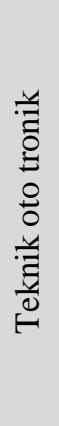 & 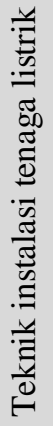 & 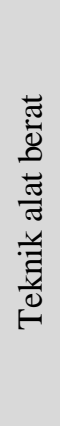 & 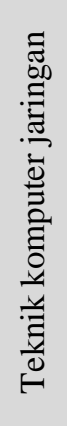 & 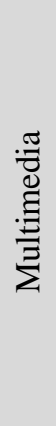 & 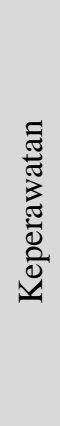 & 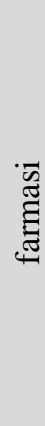 \\
\hline- & 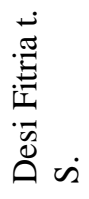 & $\stackrel{\infty}{0}$ & $\stackrel{\infty}{0}$ & $\stackrel{\infty}{0}$ & $\stackrel{\infty}{0}$ & $\stackrel{\infty}{0}$ & $\stackrel{\infty}{0}$ & $\stackrel{\infty}{0}$ & $\begin{array}{l}\infty \\
0 \\
0\end{array}$ & $\stackrel{\infty}{0}$ & $\stackrel{\infty}{0}$ & $\stackrel{\infty}{0}$ & $\stackrel{\infty}{0}$ & $\stackrel{\infty}{0}$ \\
\hline$N$ & $\begin{array}{l}\frac{.0}{3} \\
\frac{3}{0} \\
5 \\
0 \\
0\end{array}$ & $\vec{i}$ & $\begin{array}{l}n \\
0 \\
0\end{array}$ & $\overrightarrow{0}$ & $\begin{array}{l}0 \\
0 \\
0\end{array}$ & $\begin{array}{l}\text { oे } \\
0\end{array}$ & $\begin{array}{l}n \\
0 \\
0\end{array}$ & $\begin{array}{l}n \\
0 \\
0\end{array}$ & $\begin{array}{l}n \\
0 \\
0\end{array}$ & $\begin{array}{l}n \\
0 \\
0\end{array}$ & $\begin{array}{l}\tilde{6} \\
0\end{array}$ & $\stackrel{0}{0}$ & $\begin{array}{l}10 \\
0\end{array}$ & $\stackrel{n}{0}$ \\
\hline
\end{tabular}




\begin{tabular}{|c|c|c|c|c|c|c|c|c|c|c|c|c|c|c|c|}
\hline$m$ & 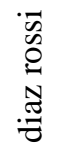 & $>$ & $\frac{a}{0}$ & $\hat{0}$ & $\hat{\sigma}$ & $\stackrel{m}{0}$ & $\begin{array}{l}\text { bु } \\
0\end{array}$ & $\begin{array}{l}\bar{\infty} \\
0\end{array}$ & $\stackrel{0}{0}$ & $\vec{\infty}$ & $\begin{array}{l}\bar{\infty} \\
0\end{array}$ & $\frac{a}{0}$ & ڤ̂ & $\stackrel{0}{0}$ & $\frac{n}{0}$ \\
\hline
\end{tabular}

Setelah mendapatkan hasil dari total weighted evaluation kemudian dilanjutkan dengan perekomendasian jurusan berdasarkan nilai weighted evaluation. Berikut ini adalah tabel ketentuan dari Nilai Weight Evaluation:

Tabel 5. Nilai Weight Evaluation

\begin{tabular}{|c|c|c|}
\hline No & Nilai & Jurusan \\
\hline 1 & $>=80$ & $\begin{array}{r}\text { Teknik alat berat, teknik instalasi listrik, teknik ototronik, } \\
\text { administrasi perkantoran, farmasi }\end{array}$ \\
\hline 2 & $>=70 .<=80$ & $\begin{array}{c}\text { Perbankan, teknik kendaraan ringan, teknik sepeda motor, } \\
\text { multimedia, teknik komputer dan jaringan }\end{array}$ \\
\hline 3 & $>=60,<=70$ & Keperawatan, perhotelan \\
\hline
\end{tabular}

Selanjutnya sistem akan memilih 3 jurusan yang nilai total weighted evaluation nya tertinggi sesuai nilai weight evaluation yang terdapat pada tabel 5 kemudian akan ditampilkan pada aplikasi Android. Apabila terdapat nilai yang sama maka akan tetap direkomendasikan juga. Jadi, dalam satu pilihan ada kemungkinan terdapat beberapa jurusan yang direkomendasikan. untuk hasil dari rekomendasi dapat dilihat pada gambar dibawah ini.

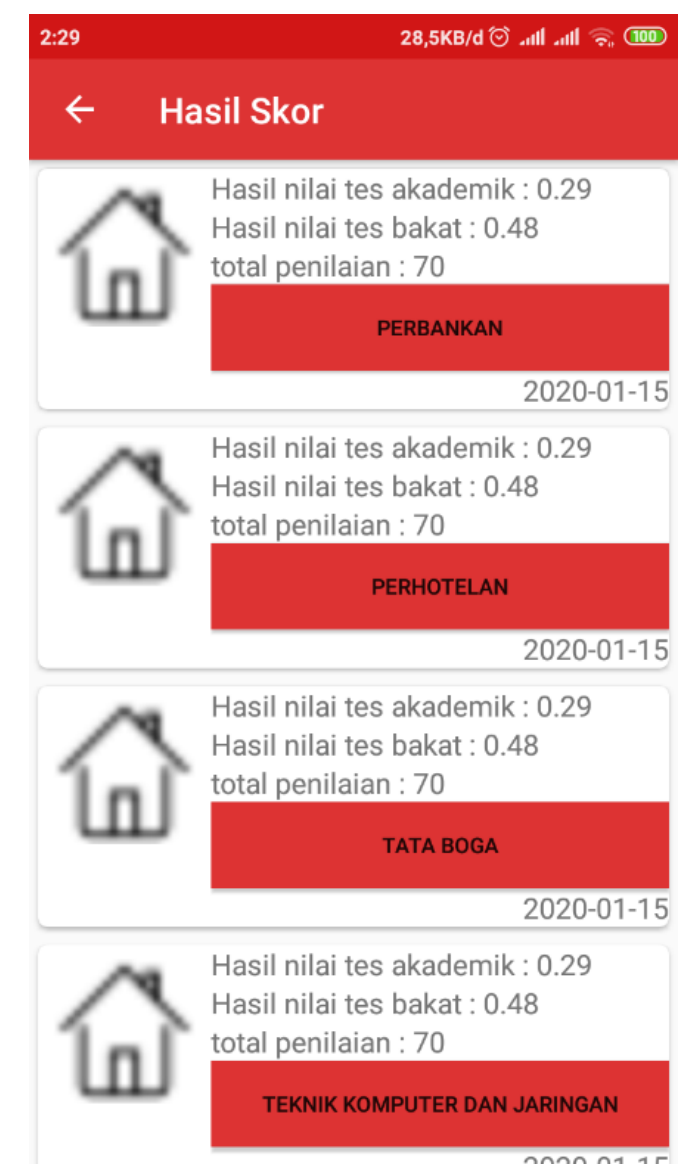

Gambar 1. Hasil Perekomendasian Jurusan 
Untuk hasil perekomendasian jurusan juga dapat dilihat pada halaman dashboard admin dan pada halaman ini dapat menampilkan semua jurusan yang direkomendasikan kepada siswa beserta nilainya. Lebih detailnya dapat dilihat pada gambar dibawah ini.

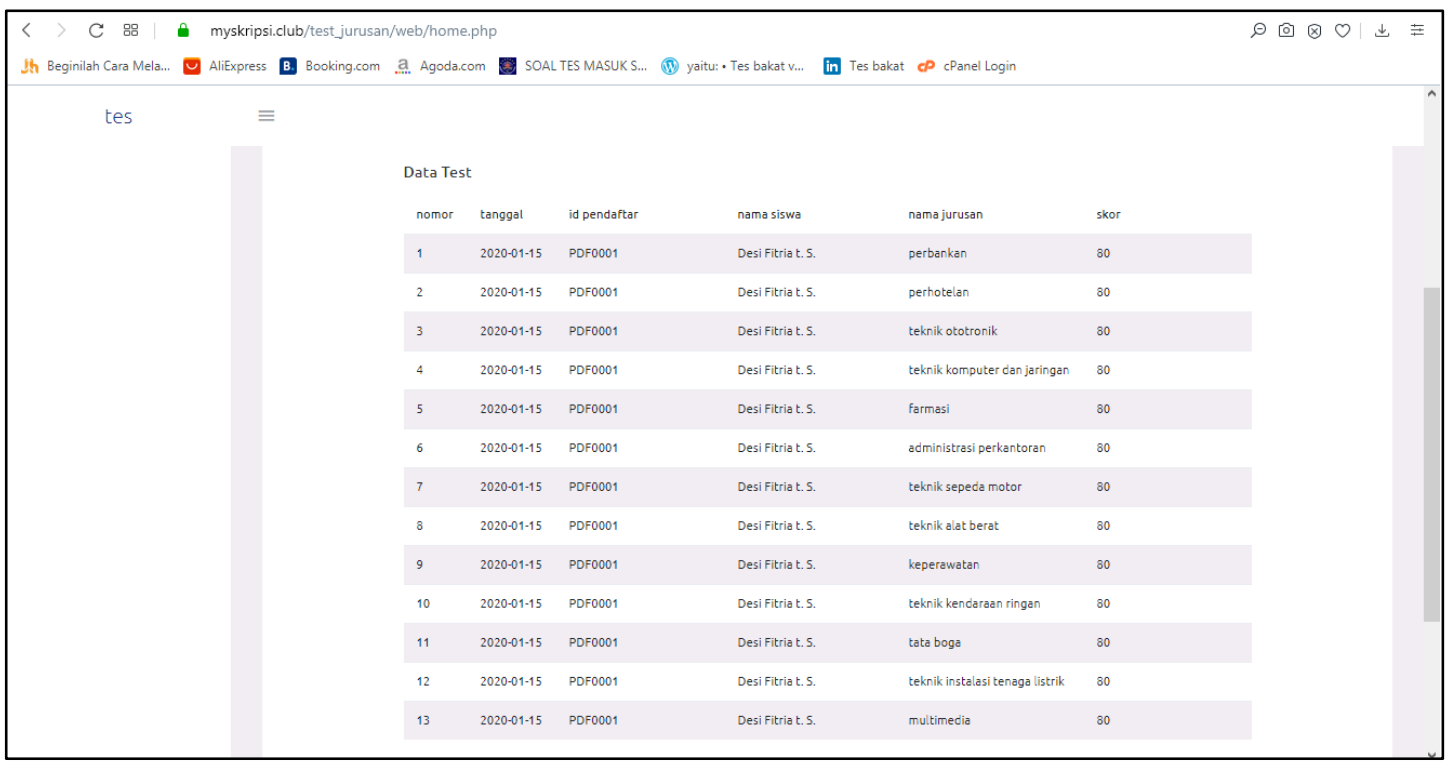

Gambar 2. Hasil Perekomendasian Jurusan Pada Halaman Admin

Lalu dilanjutkan dengan pengisian kuisioner UAT yang disebarkan kepada siswa-siswi yang mengikuti test ini yaitu sebesar 30 orang. Setelah melakukan penyebaran UAT dan mendapatkan jawaban dari responden, Hasil rata-rata perhitungan UAT diketahui sebesar 80,8\% yang menandakan banyak siswa menyatakan setuju bahwa sistem ini mudah dioperasikan dan sistem berjalan dengan semestinya.

\section{PENUTUP}

\section{Kesimpulan}

Berdasarkan penelitian yang telah dilakukan, maka dapat diambil kesimpulan terhadap sistem pendukung keputusan rekomendasi pemilihan jurusan ini yaitu, Sistem Pendukung Keputusan ini dapat mempermudah dan membantu siswa-siswi dalam mendapatkan pilihan jurusan berdasarkan hasil tes yang telah dilakukan. Didukung juga oleh hasil perhitungan UAT dengan hasil $80,8 \%$.

\section{Saran}

Pemberian saran untuk Sistem Pendukung Keputusan ini sangat amat dibutuhkan dalam pengembangan sistem kedepannya. Perlu adanya penambahan fitur menu ke dalam sistem agar lebih efisien. Sarankan untuk menerapkan metode-metode lainya agar menciptakan perbandingan antar metode dan menghasilkan pendukung keputusan yang lebih akurat.

\section{DAFTAR RUJUKAN}

Atmodiwiro, S. (2000). Pengaruh Sekolah terhadap Kecerdasan Anak. Jakarta.

Cahayatullah, Nilam. (2017). Sistem Pendukung Keputusan Penerimaan Siswa Baru Menggunakan Metode AHP di SMA NEGERI 3 Pinrang. Skripsi diterbitkan. Makassar: Sistem Informasi UIN Alauddin Makassar.

Dahria, Isha, Umi. (2014). Pendukung Keputusan Seleksi Calon Polri Baru Di Polda Kota Medan Menggunakan Metode Multifactor Evaluation Process (MFEP). 
Daihani, H. (2001). Dasar-dasar Sistem Pendukung Keputusan. Jakarta: Bina Aksara Jakarta.

Dinarga, M.S. \& Putro, R.O. \& Setiadie, H.S \& Wiedarini, A.W. \& Sucianti, Y.D.S. (2004). Jurusan Apa Buat Kamu?. Yogyakarta: Andi.

Fezanda, Daryanto, Mudafiq. (2016). Sistem Pendukung Keputusan Penjurusan Siswa Sma Menggunakan Metode Multifactor Evaluation Process (Studi Kasus: Sma Negeri 3 Bondowoso).

Khoidir, A. (2014). Sistem Pendukung Keputusan Penyeleksian Calon Siswa Baru di SMA Negeri 1 Badar Dengan Metode Multifactor Evaluation Process (MFEP). Medan: STMIK Budidarma Medan.

KEMENDIKBUD (2016). Minat Dan Bakat Siswa SMK. Jakarta.

Martuasa. (2015). Sistem Pendukung Keputusan Penentuan Siswa Berprestasi dan Penempatan Kelas Berdasarkan Peringkat Dengan Multifactor Process (Studi Kasus : SMA N 1 Medan). Medan: STMIK Budidarma Medan. 